\title{
Iodine Content in Commonly Consumed Egyptian Foods and Its Dietary Intake among Pregnant Women in Alexandria
}

\author{
Mai A. Ragab ${ }^{1}$, Samar Abd El-Mohsen², Dalia I Tayel ${ }^{2}$ \\ ${ }^{1}$ Nutrition Department, Faculty of Allied Medical Sciences, Pharos University in Alexandria, \\ Egypt. (+2)01092837809.mai.ragab@pua.edu.eg \\ ${ }^{2}$ Nutrition Department, High Institute of Public Health, Alexandria University, Egypt \\ (+2) 01550819946.samarmo7sen@yahoo.com // (+2) \\ 01092744474.dalia2tayel@yahoo.com
}

\section{ABSTRACT}

Iodine is one of the most important trace elements in human nutrition. Maternal iodine deficiency during pregnancy results in fetal iodine deficiency. Iodine content of foods depends on its content in the soil that grown in it.The highest dietary iodine content was found in milk and milk products group followed by vegetables and the lowest iodine content was found in fruits. About one third $(28.8 \%)$ of pregnant women had iodine inadequate intake. Daily intake of iodine among pregnant women was $330 \mu \mathrm{g} / \mathrm{day}$. The highest dietary iodine content was found in milk and milk products group followed by vegetables and the lowest iodine content was found in fruits. Iodine inadequacy was prevalent among pregnant women attending health care facilities in Alexandria based on their dietary intake. Intake of dietary supplements containing iodine during pregnancy is recommended, with regular follow up of iodine status for pregnant women.

Keywords: Pregnancy, iodine, thyroid diseases, iodine.

\section{*Corresponding author:Mai A. Ragab( Mai Abdallah Ragab)}

\section{INTRODUCTION}

Iodine is one of the most important trace elements in human nutrition. It forms a vital component of thyroid hormones as thyroxin (T4) and tri-iodothyronine (T3). Thyroid hormonesare crucial regulators of the metabolic rate, and physical and mental development in humans. The biological function of the T4 and T3 encompasses the regulation of mitochondrial energy metabolism as well ascellular oxidation, thermoregulation, intermediate metabolism, carbohydrate, lipid and protein metabolism, and nitrogen retention. ${ }^{[1]}$ They are particularly necessary during early growth, development and maturation of most organsasthe development of brain, hearing, vision, muscles, heart, pituitary gland, kidney, reproductive system, and bones. ${ }^{[2]}$

Iodine content of foods depends on its content in the soil that grown in it. Due to glaciations, flooding, rivers changing course and deforestation, the iodine present in top soil is constantly leached. This in turn leads to deficiency of iodine in crops grown on iodine deficient soil with consequently low iodine in the diet for livestock and humans. ${ }^{[3]}$ Seawater is a rich source of iodine. Seaweeds and fish, which thrive on seaweeds, are also rich in iodine. Thus, populations living near the sea and consuming seaweeds and reef fish such as the Japanese have a high dietary intake of iodine. A wide variety of food contains iodine 
including eggs, meat, milk and milk products, cereal grains, dried legumes, dried vegetables and dried fruits, but the good sources are limited to marine fishes and shellfish. The iodine content of foods varies with geographic location, ranging widely from 30 to $800 \mu \mathrm{g} / 100$ gflesh. ${ }^{[4]}$ The most important source of iodine is iodized salt supplemented with $20 \mathrm{mg}$ potassium iodate per $\mathrm{kg}$ of sodium chloride. Consumption of $4-5 \mathrm{~g}$ salt provides $60-80 \mu \mathrm{g}$ iodine daily. This supply must be complemented by iodine rich foods. ${ }^{[5]}$

Iodine deficiency disorders (IDD) represents all the negative health consequences of low iodine intake on the growth and the development, which could be totally prevented by adequate iodine intake. ${ }^{[6]}$ Studies done in Egypt over the last half century revealed thatIDD is prevalent in most governorates of Egypt constituting a major public health problem, with varying degrees of severity. It ranged between severe public health problem in New Valley and some governorates of Upper Egypt to mild/moderate in others. ${ }^{[7,8]}$ Iodine deficiency is the most common cause of cognitive impairment. Even a mild iodine deficiency may seriously affect the intelligence and function of children. ${ }^{[9]}$ Maternal iodine deficiency during pregnancy results in fetal iodine deficiency. It is accompanied by higher rates of stillbirths, abortions and congenital abnormalities. It constitutes a threat to early brain development with consequent physical and mental retardation and lower cognitive and motor performance in later life. ${ }^{[10,11]}$ Dietary Reference Intake (DRI) of iodine for pregnant women is 220 $\mu \mathrm{g} / \mathrm{day}{ }^{[12]}$

Several methods, including spectrophotometry, have been used for iodine determination in biological matrices. Spectrophotometric method is the most commonly used method for iodine analysis in biological and food samples. ${ }^{[13]}$ There are five Association of Official Analytical Chemists (AOAC) methods available for iodine analysis in foods, which include titration, reversed-phase ion-pair liquid chromatography, ion-selective electrode and Inductively Coupled Plasma Mass Spectrometry (ICP-MS), which give reliable and accurate results. ${ }^{[14]}$

The recommended indicator for evaluating iodine intake in a population are measurements of urinary iodine concentration, thyroid size and the serum thyroglobulin concentrations. ${ }^{[15]}$ Also, lack ofiodine in Egyptian Food Composition Table and limited data about dietary iodine intake among pregnant women in Egypt. So,the present study aimed to assessiodine content in traditional foods in Egypt and to determine its dietary intake among pregnant women as group at risk of iodine deficiency in Alexandria.

\section{MATERIALS AND METHODS}

\subsection{Study design and Sampling}

A cross sectional studywas conductedon400 pregnant women at the third trimester attending family health centres in Alexandria, Egypt during the period from August to December 2016.The studied sample of pregnant women was selectedusing a stratified sampling technique.Six districts were randomly selected from a list containing 8 health districts in Alexandria. One family health center was selected at random from each district. The required sample size was distributed between family health centers by proportional allocation method according to number of pregnant women attending the selected facilities, yielding 149 pregnant women from Karmouz, 69 pregnant woman from El-Mandara, 52 pregnant woman from Somoha, 64 pregnant woman from MoharamBek, 34 pregnant woman from El-Gomrouk, and 32 pregnat woman from El-Dekhila health care facility. Pregnant women in first and second trimester and pregnant women with preexisting thyroid disease were excluded from the study. Identical samples of 70 food items which consumed by each pregnant woman were subjected to cook by the main traditional and usual methods of Egyptian cooking methods and prepared for determination of iodine. 


\subsection{Data collection}

A predesigned interviewing questionnaire was used to collect data from each pregnant woman. Data about socioeconomic characteristics asmaternal age, educational level which classified into low (illiterate, primary), middle (preparatory, secondary), and high (university), occupation; and medical history (presence of any chronic disease, dietary supplements usage, family history of any chronic disease, increase blood glucose or blood pressure during pregnancy, and presence of anemia during pregnancy) were collected.

Dietary intake data were collected from each pregnant woman using food frequency questionnaire method to determine dietary intake of iodine.Each pregnant woman was asked about consumption (amount and frequency) of all food items during the previous week with stress on food rich in iodine to get daily consumption of each food item (g/day). Each subject was asked to indicate how often on the average she consumed each food item (number of times per day, per week or less than that). [16] To get the mean daily intake of iodine, samples of identical foods consumed by the pregnant women were obtained from the main markets in Alexandria to be cooked and analyzed for its iodine contents.

\subsection{Determination of iodine content in food $(\mu \mathrm{g} / \mathrm{g})$}

Identical 70 samples of all foods were subjected to cooking by the main traditional and usual methods of Egyptian cooking and were prepared for determination of iodine content. One gram of food is properly homogenized through mincing, grinding or blending. Samples were examined freshly, or they kept deeply frozen and stored in sterile plastic containers. All food samples were prepared for spectrophotometric detection of iodine according to Maxon et al(1980) method. ${ }^{[17]}$ Spectrophotometric method is the most commonly used method for reducing Ce (IV) to Ce (III) by As (III), in acid medium. The principle of the measuring is the reduction of the yellow color of ceric to the colorless of cerous. ${ }^{[18]}$

\subsection{Estimation of daily intake of iodine ( $\mu \mathrm{g} / \mathrm{day})$}

Daily iodine intake for each pregnant woman was calculated in ( $\mu \mathrm{g} /$ day) by multiplication of iodine content of each food sample $(\mu \mathrm{g} / \mathrm{g})$ by daily consumption of the same food item for each pregnant woman (g/day).Adequacy of iodine intake was calculated as follows: actual iodine intake of each pregnant women / DRI of iodine during pregnancy $x$ 100. Inadequate intake was considered if iodine intake was less than the recommended amount and percent adequacy was less than $100 \%$.

\subsection{Statistical analysis}

Data management was conducted using the Statistical Package for Social Science (SPSS) version "21" software. Data was presented tabular, graphically, mathematically using mean and standard deviation (SD). ${ }^{[19]}$ Descriptive statistics included minimum (Min), maximum (Max), arithmetic mean, standard deviation (SD), and median were calculated.

\subsection{Ethical considerations}

This study was conducted according to the guidelines laid down for medical research involving human subjects and was approved by Ethics Committee of High Institute of Public Health, Alexandria University, Egypt. All information was taken following all privacy procedures and all collected data were kept confidential. Verbal consent was obtained from every pregnant woman after she was informed about the study purpose and procedure. There was no any conflict of interest. 


\section{RESULTS}

From Table 1, it was observed that atotal of 400 pregnant women aged between 22 to 35 years with meanage of $26.36 \pm 5.61$ years. The highest percent of pregnant women were housewives and had low educational level ( $92 \%$ and $48.75 \%$ respectively). The majority of them $(96.5 \%)$ had normal blood glucose level and normal blood pressure. More than half of them $(58.8 \%)$ had anemia during current pregnancy. Iron and calcium supplements were consumed by $92.3 \%$ and $82.5 \%$ of pregnant women and only $28.7 \%$ ofthem use folic acid supplement.

Table1. Socioeconomic characteristics and medical history of the studied sample of pregnant women

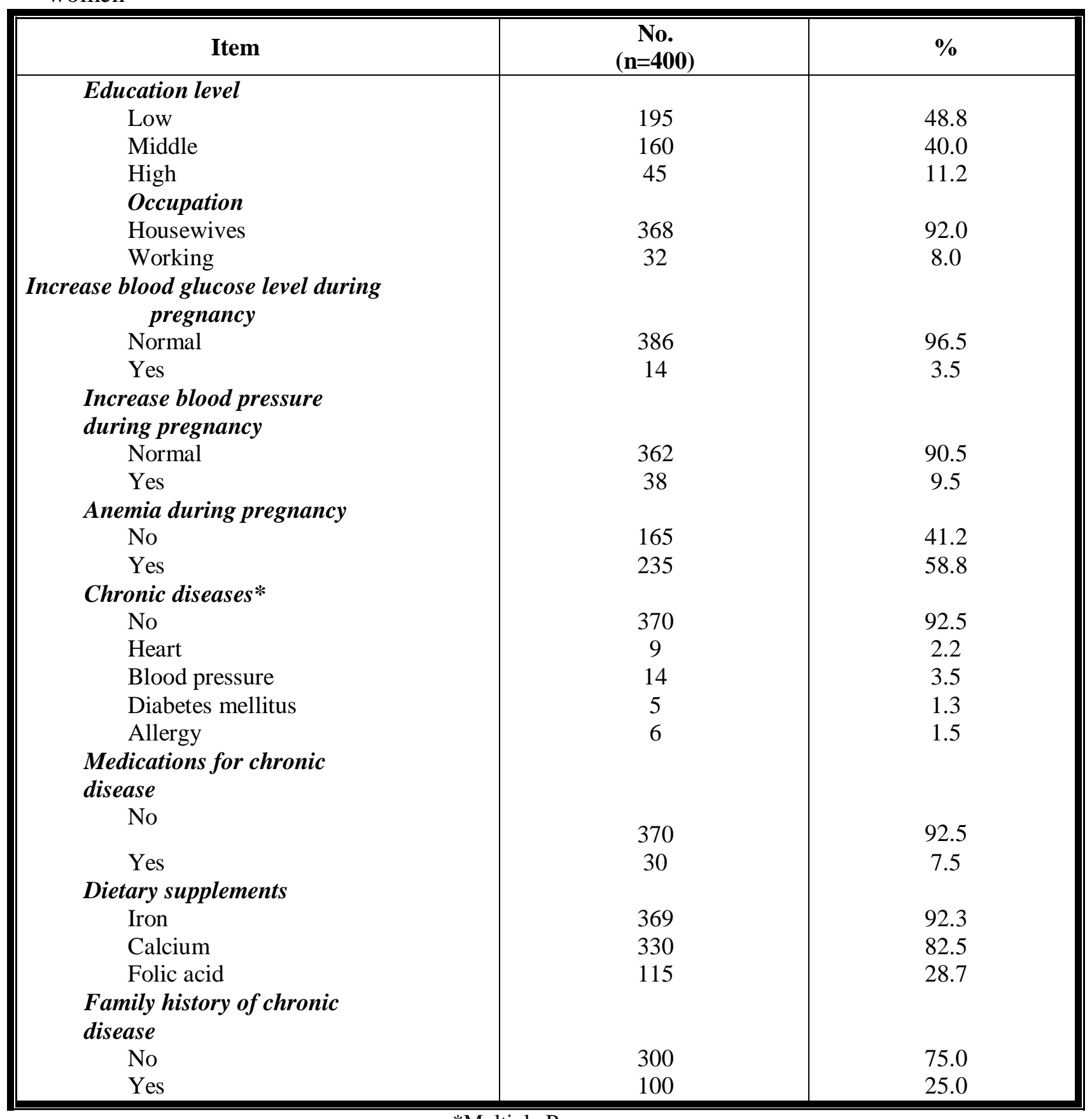

*Multiple Responses 
Figure 1 shows the highest iodine content was found in milk and milk products $(0.255 \pm 0.005 \mu \mathrm{g} / \mathrm{g})$, followed by vegetables $(0.242 \pm 0.007 \mu \mathrm{g} / \mathrm{g})$, while the lowest iodine content was found in fruits $(0.146 \pm 0.005 \mu \mathrm{g} / \mathrm{g})$.

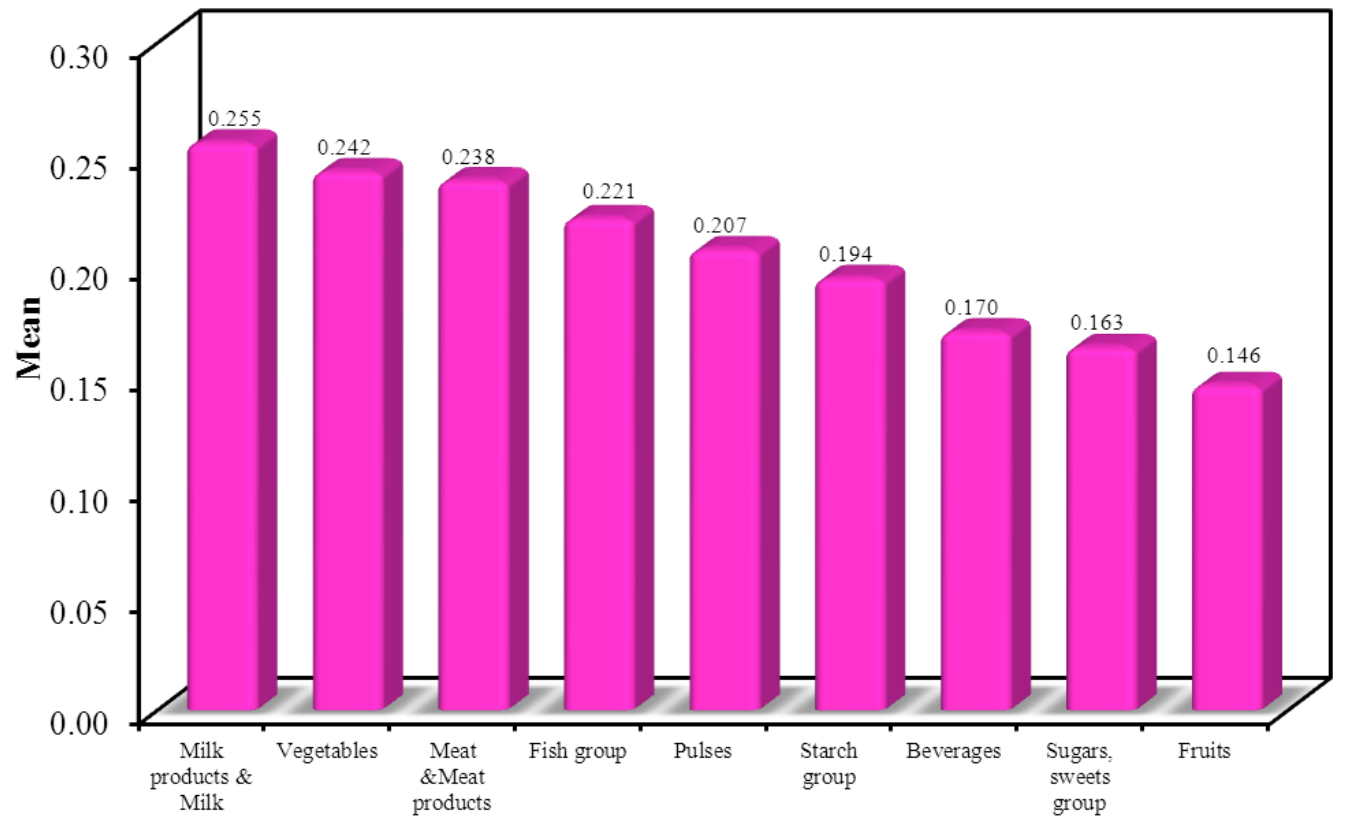

Fig 1: Average iodine content of commonly consumed Egyptian food groups $(\mu \mathrm{g} / \mathrm{g})$

In Figure 2, beverages had the highest daily consumption among pregnant women $(224.509 \pm 187.88 \mathrm{~g} /$ day $)$, followed by fruits $(66.16 \pm 55.50 \mathrm{~g} /$ day $)$, then starch group $(59.863 \pm 42.520 \mathrm{~g} /$ day), while sugar and sweets had the lowest daily consumption among pregnant women.

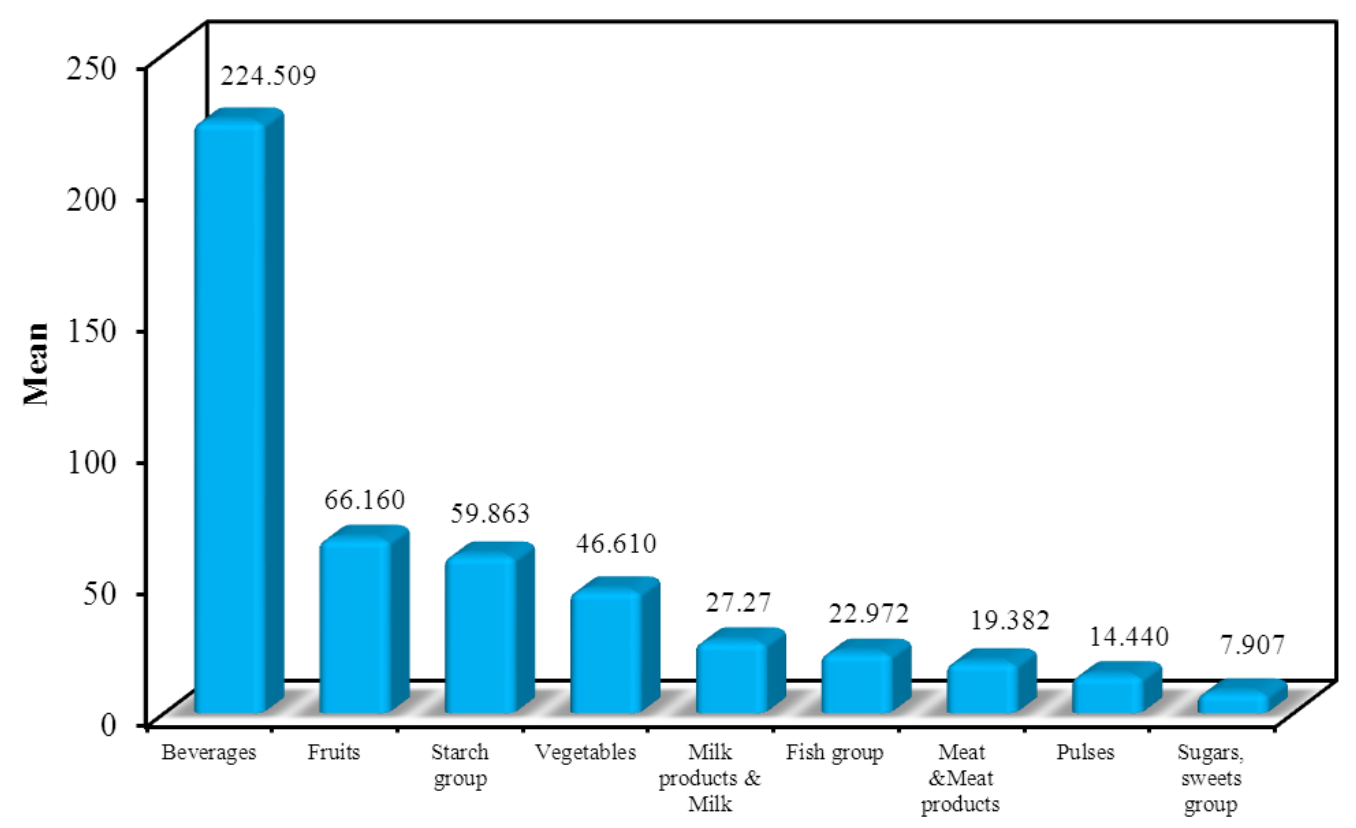

Fig 2: Average daily consumption of different food groups containing iodine among pregnant women (g/day) 
As shown in figure 3 the highest dietary intake of iodine among pregnant women came from beverages $(270.22 \pm 27.92 \mu \mathrm{g} /$ day $)$, followed by fruits group $(115.89 \pm 8.10 \mu \mathrm{g} / \mathrm{day})$, then starch group $(82.54 \pm 8.43 \mu \mathrm{g} /$ day $)$, while the lowest dietary intake of iodine came from sugar and sweets $(3.73 \pm 1.06 \mu \mathrm{g} /$ day $)$.

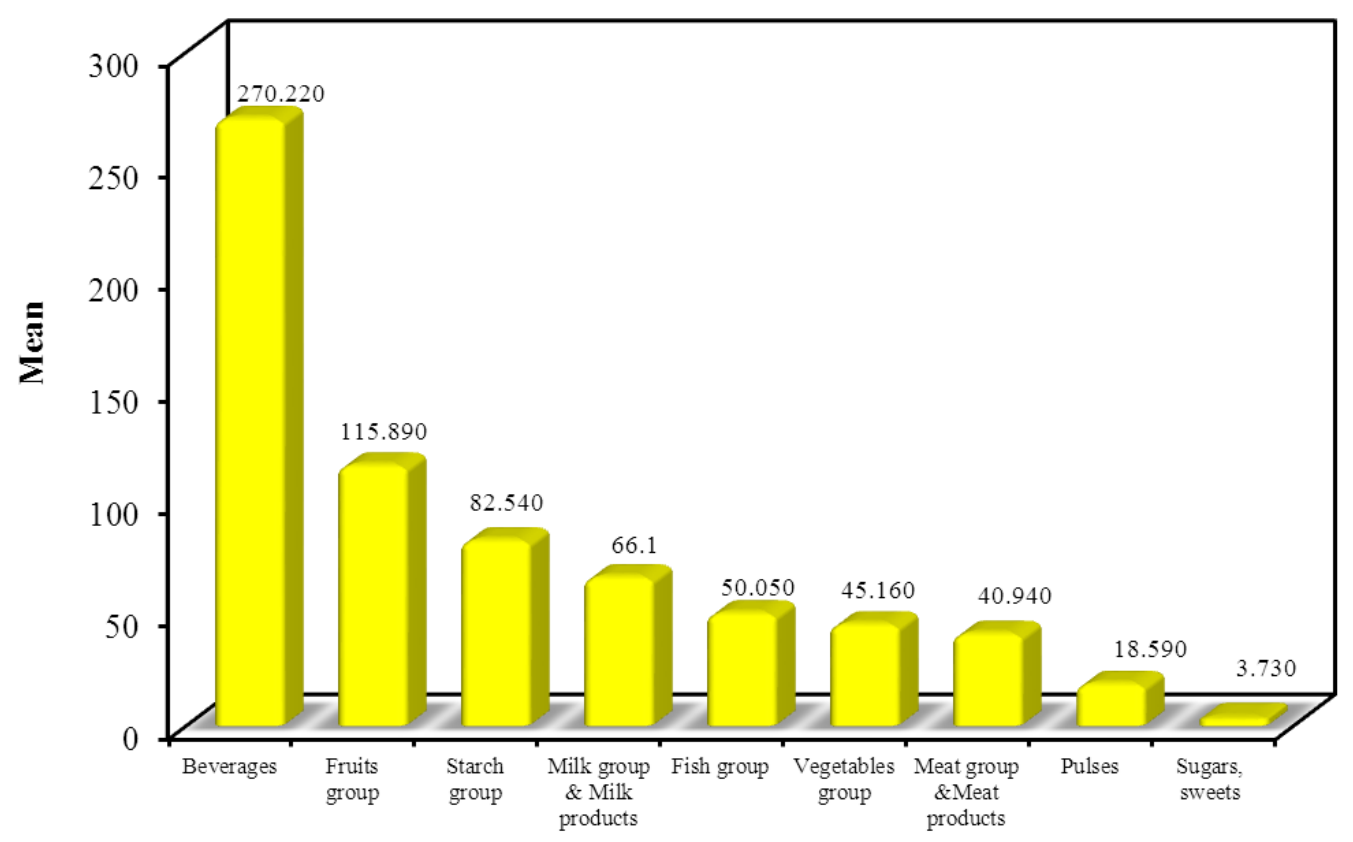

Fig 3: Dietary iodine intake ( $\mu \mathrm{g} /$ day) among pregnant women from different food items

Table 2 shows iodine intake and adequacy for pregnant women. Daily intake of iodine among pregnant women was $330 \mu \mathrm{g} / \mathrm{day}$ and $71.2 \%$ of pregnant women consumed adequate amount of iodine, while about one third of them (28.8\%) consumed amount of iodine less than their requirements during pregnancy.Iodine content of foods is highly variable between food categories as well as within each category. The richest sources are marine products (such as fish, shellfish, mollusks, seaweed), eggs and milk, as well as their derivatives and iodized salt. ${ }^{[18]}$ on contrast, the highest iodine content in current study was found in milk and milk product, followed by vegetables while the lowest iodine content was in fruits.Table2. Total intake and adequacy of iodine among pregnant women

\begin{tabular}{|c|c|c|c||}
\hline Item & Min. - Max. & Mean \pm SD & Median \\
\hline Total iodine intake $(\boldsymbol{\mu}$ g/day) & $125.2-1079.8$ & $389.3 \pm 227.9$ & 330.0 \\
\hline Iodine adequacy & \multicolumn{3}{|c||}{ No. $(\%)$} \\
Inadequate & \multicolumn{3}{|c}{$115(28.8)$} \\
Adequate & $285(71.2)$ \\
\hline
\end{tabular}




\section{DISCUSSION}

Iodine content of milk in current study was $255 \pm 0.005 \mu \mathrm{g} / \mathrm{L}$ that was near to iodine content of milk $(225.59 \pm 97.92 \mu \mathrm{g} / \mathrm{L})$ in study done in Iran. ${ }^{[20]}$ In the USA, the concentration of iodine in milk fell from 1975 to 1982 , and remained relatively stable from 1982 to 1990 with concentrations around $230 \mu \mathrm{g} / \mathrm{L}$ which was almost near iodine content of present study. ${ }^{[21]}$ A higher iodine content in milk $(454 \mu \mathrm{g} / \mathrm{L})$ was reported in study done in Boston. A very low iodine content in milk $(50 \mu \mathrm{g} / \mathrm{L})$ was reported in Australia in 1982 and raised to $300 \mu \mathrm{g} / \mathrm{L}$ in 2005 , with $16 \%$ of the samples above $500 \mu \mathrm{g} / \mathrm{L} .{ }^{[22]}$ The variation of iodine content of milk and milk products may be due to iodine intake of dairy cows, goitrogen intake, milk yield, season, teat dipping with iodine-containing disinfectants, type of farming and processing. ${ }^{[23]}$ Iodine content of dairy products varies according geographical origin of the milk, natural iodine content of the feed, drinking water given to the cows, vitamin and minerals feed added to enrich the diets, veterinary drugs and milking machine disinfectants and food processing applications. ${ }^{[24]}$

The low content of iodine in vegetables and fruits was $0.132-0.379 \mu \mathrm{g} / \mathrm{g}$ and 0.081 $0.239 \mu \mathrm{g} / \mathrm{g}$, respectively in the present study which may be due to iodine deficiency in soil. A study done in Egypt by High Institute of Public Health with collaboration of UNICEF demonstrated that environmental iodine deficiency was the main etiologic factor for goitrogenesis in Egyptas evidenced by its low content in soil, drinking water, and most consumed food items. ${ }^{[7]}$

The iodine content in fishes varies highly because classification of fish populations according to iodine concentration is however difficult as there is large variation between fishes of the same species. Karl et al reported that iodine concentrations in fish found to be in the range $0.39-6.9 \mu \mathrm{g} / \mathrm{g}$ that was consistent iodine content of fish $(0.221 \pm 0.003 \mu \mathrm{g} / \mathrm{g})$ in the current study. ${ }^{[25]}$

In the current study, pregnant women highest iodine intake was obtained from beverages $(270.22 \pm 27.92 \mu \mathrm{g} /$ day), fruits $(115.89 \pm 8.10 \mu \mathrm{g}$ /day) and starch group (82.54 \pm 8.43 $\mu \mathrm{g} / \mathrm{day})$ and the lowest intake obtained from sugar and sweets $(3.73 \pm 1.66 \mu \mathrm{g} / \mathrm{day})$. On contrast in Norwegian, The highest iodine intake was obtained from dairy products $76 \mu \mathrm{g} /$ day, fish $33 \mu \mathrm{g} / \mathrm{day}$, eggs $7 \mu \mathrm{g} /$ day, bread $6 \mu \mathrm{g} / \mathrm{day}$ and lowest iodine intake from meat and meat products group. ${ }^{[26]}$ In Switzerland, based on direct food analysis, mean intake of dietary iodine is approximately $140 \mu \mathrm{g} / \mathrm{d}$, mainly from bread and dairy products. ${ }^{[27]}$

The present study revealed that $28.8 \%$ of pregnant women had in adequate iodine intake. This finding agrees with many results performed in different countries which concluded that iodine deficiency among pregnant women was prevalent with varying degrees. ${ }^{[28-30]}$ In Egypt, $34.5 \%$ of pregnant women who attended outpatient obstetric clinic at Ain Shams University Hospital in Cairo had clinical or subclinical hypothyroidism indicating inadequacy of iodine which was consistent with the results of current study. ${ }^{[30]}$ Similarly, Abd El Mohsen S reported that $31.3 \%$ of pregnant women in Alexandria, 2014 had iodine deficiency where urinary iodine concentration was lower than $150 \mu \mathrm{g} / \mathrm{l} .{ }^{[28]}$ Measurement of urinary iodine concentration is considered an accurate indicator of dietary iodine. ${ }^{[31]}$ In The present study iodine adequacy was estimated based on dietary intake data of pregnant women and revealed that $31.3 \%$ of pregnant women had in adequate iodine intake. Similarly, Hamza et al, 2008 reported that $29.2 \%$ of pregnant women had iodine deficiency. ${ }^{[2]}$ Another study revealed that $30.7 \%$ of pregnant women had varying degree of iodinedeficiency based on urinary iodine concentration. ${ }^{[33]}$ So estimation of iodine in diet may be good indicator as urinary iodine reflecting iodine nutrition status as pregnant women. 


\section{CONCLUSION}

Iodine inadequacy was prevalent among pregnant women attending health care facilities in Alexandria based on their dietary intake. About one third (28.8\%) of pregnant women had iodine inadequate intake. Daily intake of iodine among pregnant women was $330 \mu \mathrm{g} / \mathrm{day}$. The highest dietary iodine content was found in milk and milk products group followed by vegetables and the lowest iodine content was found in fruits. Beverages (which deficient in iodine) had the highest daily consumption among pregnant women, followed by fruits then starch group, while sugar and sweets had the lowest daily consumption among them.

\section{RECOMMENDATIONS}

Nutrition education for pregnant women about dietary sources of iodine, importance and outcomes of iodine deficiency is recommended.Intake of dietary supplements containing iodine during pregnancy is encouraged. Regular follow up of iodine nutrition status for pregnant women either by dietary assessment or by estimation of urinary iodine concentrationis needed.

\section{RFERENCES}

1. Krassa GE, Poppe K, Glinoer D. Thyroid function and human reproductive health. Endocr Rev. 2010; 31: 702-55.

2. Winkler R. Iodine A potential antioxidant and the role of iodine/iodide in health and disease. Natural Sci. 2015; 7: 548-57.

3. Chandrakant S, Panda V, Kapil Y, Rahul S, Rijuta P. Iodine deficiency disorders (IDD) control in India. Indian J Med Res. 2013; 138: 418-33.

4. Koutras DA, Matovinovic J, Vought R. The ecology of iodine. In: Stanbury JB, Hetzel BS (eds). Endemic goitre and endemic cretinism. Iodine nutrition in health and disease. New Delhi: Wiley Eastern Limited; 1985.pp.185-95.

5. Judprasong K,JongjaithetN,Chavasit V. Comparison of methods for iodine analysis in foods. Food Chem. 2016; 193: 12-7.

6. Ivanova L.Iodine Deficiency Disorders and Salt Iodization - Public Health Implications. J Nutr Health Food Eng. 2015; 2(1):1-2.

7. El-Sayed NA, Mahfouz AR, Nofal L, Ismail HM, Gad A, Abu Zeid H. Iodine deficiency among School children in upper Egypt: an epidemiologic study. J Trop Pediatr.1998; 44: 270-4.

8. El Sayed NA. Profile of iodine deficiency disorders in Egypt compilation of studies: Assignment Report. Egypt: High Institute of Public health, UNICEF, Ministry of Health and Population; 1998. p.28.

9. Santiago FP, Torres BR, Muela MJ, Rojo MG, Garcia FE, Garriga M, et al. Intelligence quotient and iodine intake: a cross- sectional study in children. J ClinEndocrinolMetab. 2004; 89(8): 3851-7.

10. Zimmermann MB. The effects of iodine deficiency in pregnancy and infancy. Paediatr Perinat Epidemiol. 2012; 26 (Suppl 1): 108-17.

11. Zimmermann MB, Jooste PL, Pandav CS. Iodine-deficiency disorders. Lancet. 2008; 372 (9645): 1251-62.

12. Food and Nutrition Board, Institute of Medicine, Dietary Reference Intakes, Washington, DC: National Academy Press; 2001. p. 258.

13. Judprasong K, Jongjaithet N, Chavasit V. Comparison of methods for iodine analysis in foods. Food Chem. 2016;193:12-7. 
14. Gaithersburg M. Official Methods of Analysis of AOAC International. $20^{\text {th }}$ ed. USA: AOAC. 2016.

15. Briel T van den, West CE, Hautvast JG, van den Briel T, West CE, Hautvast JG, et al. Serum thyroglobulin and urinary iodine concentration are the most appropriate indicators of iodine status and thyroid function under conditions of increasing iodine supply in schoolchildren in Benin. J Nutr. 2001; 131(10):2701-6.

16. Hammod KA. Intake: Analysis of the diet. In: Mahan LK, Escott-stumps S, Raymond JL, editors. Krause's food and nutrition care process. $14^{\text {th }}$ ed. Missouri: Elsevier Saunders; 2017.p.52-63.

17. Moxon RE, Dixon EJ. Semi-automatic method for the determination of total iodine in food. Analyst. 1980;105(1249):344-52.

18. Shelor CP, Dasgupta PK. Review of analytical methods for the quantification of iodine in complex matrices. Anal ChimActa. 2011; 702(1):16-36.

19. Kirkpatrick LA, Feeney BC. A simple guide to IBM SPSS statistics for version 20.0. Student ed. Belmont, Calif.: Wadsworth, Cengage Learning; 2013.

20. Shakerian A. Iodine Determination in Raw Cow's Milk in Iran. J Food Biosci Technol. 2014; 4(1):13-20.

21. Pennington JA. Iodine Concentrations in US Milk: Variation Due to Time, Season, and Region. J Dairy Sci. 1990; 73(12):3421-7.

22. Hejtmánková A, Kuklík L, Trnková E, Dragounová H. Iodine concentrations in cow's milk in Central and Northern Bohemia. Czech J Anim Sci. 2006; (5):189-95.

23. Delange F. Iodine deficiency as a cause of brain damage. Postgraduate Medical Journal. 2001; 77:217-20.

24. Haddow JE, Palomaki GE, Allan WC. Maternal thyroid deficiency during pregnancy and subsequent neuropsychological development of the child. New Engl J Med. 1999; 341:549-55.

25. Karl H, Münkner W, Krause S, Bagge I. Determination, spatial variation and distribution of iodine in fish. Dtsch Leb. 2001; 97:89-96.

26. Marine D, Kimball OP. Prevention of simple goiter in man. Archives of Internal Medicine. 1920; 25:661-72.

27. Stanbury JB etal. Iodine-induced hyperthyroidism: occurrence and epidemiology. Thyroid.1998; 8: 83-100.

28. Abd El-Mohsen S. A Study on iodine nutrition status of pregnant women in Alexandria (Thesis). Alexandria University; 2014.

29. World Health Organization (WHO). Assessment of iodine deficiency disorders and monitoring their elimination: A guide for programme managers. 3rd ed. Geneva, Switzerland: WHO; 2007.

30. Ahmed IZ, Eid YM, El Orabi H, Ibrahim HR. Comparison of universal and targeted screening for thyroid dysfunction in pregnant Egyptian women. Eur J Endocrinol. 2014; 171(2):285-91.

31. Zimmermann MB. Symposium on 'Geographical and geological influences on nutrition': Iodine deficiency in industrialized countries. ProcNutr Soc. 2010; 69(1):13343.

32. Hamza RT, Youssef AM, Mouharam WA, El DanasouryAS.Maternal and neonatal iodine nutrition in Cairo. The Internet Journal of Pediatrics ad Neonatalogy.2008;8(2):700-14.

33. Igwe KO, Ukoha AI, NwaChukwu N. Ujowundu CO. Iodine nutrition for pregnant women in three major villages of Ohafia local government area in Abia State of Nigeria. African Journal of Biochemistry Research. 2011; 5(2):69-71. 